\title{
Produção, propriedades e aplicações de oligossacarídeos
}

\section{Production, properties and applications of oligosaccharides}

\author{
Ellen Cristine Giese ${ }^{1 *}$; Tatiana Hirosi²; Maria de Lourdes Corradi da Silva ${ }^{3}$; \\ Roberto da Silva ${ }^{4}$; Aneli de Melo Barbosa ${ }^{5}$
}

\begin{abstract}
Resumo
Os oligossacarídeos participam da constituição da fibra alimentar e são principalmente utilizados como prebióticos. Esta revisão apresenta as vias de obtenção destes açúcares, os quais podem ser produzidos por síntese (química ou enzimática) ou da despolimerização de polissacarídeos (física, química ou enzimática), como descrito na presente revisão. Os oligossacarídeos vêm sendo utilizados comercialmente como ingredientes de cosméticos, medicamentos, produtos agrícolas e principalmente na indústria alimentícia. O potencial de aplicações dos oligossacarídeos nessas áreas nas mais diversas áreas tais como alimentos, rações animais, fármacos e cosméticos tem contribuído para o aumento das investigações científicas. O uso de oligossacarídeos como agentes imunomoduladores e modificadores de respostas biológicas foi recentemente descrito, assim como seus efeitos como compostos antiinflamatórios e hipocolesterolêmicos. Uma visão geral sobre as diversas funções nutracêuticas e biológicas destes oligômeros de carboidratos visando benefícios para a saúde humana também foi reportada.
\end{abstract}

Palavras-chave: Oligossacarídeos. Fibras da dieta. Saúde humana.

\begin{abstract}
Oligosaccharides participate in the formation of dietary fiber and are mainly used as prebiotic agents. This review presents ways of obtaining these sugars, which can be produced by synthesis (chemical or enzymatic), or through depolymerization of polysaccharides (physical, chemical or enzymatic). Oligosaccharides have also been used commercially as an ingredient in cosmetics, pharmaceuticals, agricultural products and especially in the food industry because of their physical properties. The potential applications of oligosaccharides in several areas such as food, animal feed, pharmaceuticals and cosmetics have contributed to the increase in scientific research on these carbohydrates. The use of oligosaccharides as immuno-modulatory agents and biological response modifiers has been recently described, and their effects as anti-inflammatory and in reducing cholesterol. An overview of the various nutraceutical and biological functions of these carbohydrates in order to benefit human health is also reported.
\end{abstract}

Key words: Oligosaccharides. Dietary fibers. Human health.

1 Dra em Engenharia e Ciências de Alimentos, IBILCE, UNESP, São José do Rio Preto, SP, Brasil. E-mail: ellengiese@gmail.com

2 Especialista em Bioquímica Aplicada, Depto de Bioquímica e Biotecnologia, CCE, UEL, Londrina, PR, Brasil. E-mail: tatianahirosi@yahoo.com.br

3 Prof ${ }^{a}$ do Depto de Física, Química e Biologia, FCT, UNESP, Presidente Prudente, SP, Brasil. E-mail: corradi@fct.unesp.br

4 Docente do Depto de Química e Ciências Ambientais, IBILCE, UNESP, São José do Rio Preto, SP, Brasil. E-mail: dasilva@ ibilce.unesp.br

5 Prof ${ }^{\mathrm{a}}$ do Depto de Bioquímica e Biotecnologia, CCE, UEL, Londrina, PR, Brasil. E-mail: aneli@uel.br

* Autor para correspondência

Recebido para publicação 07/04/2009 Aprovado em 04/04/201 1 


\section{Introdução}

Os polissacarídeos são macromoléculas de ocorrência natural e exercem funções bastante variadas em todos os organismos vivos. Estes biopolímeros são formados pela condensação de monossacarídeos ou seus derivados oligossacarídeos, que se unem através de ligações glicosídicas originando compostos de alta massa molecular e propriedades físico-químicas e biológicas peculiares (SUTHERLAND, 1998).

As modificações físicas, químicas ou enzimáticas dos polissacarídeos nativos vêm sendo utilizadas buscando o aumento de sua funcionalidade. A despolimerização destas moléculas resulta em fragmentos menores, com grau de polimerização (GP) que variam de duas até aproximadamente treze unidades monossacarídicas, denominados oligossacarídeos. Estes carboidratos participam da constituição da fibra alimentar e são parcialmente digeridos por seres humanos, no qual as porções não digeríveis servem como alimentos para as bactérias que fazem parte da flora natural tais como a bifidobactérias e lactobacilos (PASSOS; PARK, 2003).

Alguns oligossacarídeos são encontrados na forma livre em frutas, vegetais, leite e mel, como os dissacarídeos lactose e sacarose; outros como a maltose e a celobiose são obtidos a partir de hidrólise química ou enzimática do amido e celulose, respectivamente (HIRAYAMA, 2002; ALMEIDA; PASTORE, 2004). Hexassacarídeos, heptassacarídeos e nonassacarídeos também têm sido obtidos por via sintética, através de reações de síntese orgânica mediadas por enzimas microbianas como hidrolases e transferases (MONSAN; PAUL, 1995).

O grande potencial de aplicações destes açúcares nas áreas de alimentos, rações animais, fármacos, cosméticos e também como agentes imunomoduladores e prebióticos tem promovido a condução de novas pesquisas para viabilizar sua obtenção e elucidar suas propriedades biológicas e funcionais (REMAUD-SIMEON et al., 2000). Os oligossacarídeos podem ser utilizados em processos biológicos de reconhecimento, como infecções virais e bacterianas, adesão celular, transdução de sinais e comunicações intercelulares (WONG, 1995; DAVIES; CHARNOCK.; HENRISSAT, 2001).

A síntese de oligossacarídeos é dificultada pelo número de possibilidades de combinação entre as unidades monoméricas de açúcares e a introdução estéreo-específica de ligações glicosídicas (TOLSTOGUZOV, 2004; BARRETEAU; DELATTRE; MICHAUD, 2006). Os oligossacarídeos bioativos podem ser obtidos através de síntese (química ou enzimática) ou da despolimerização de polissacarídeos (física, química ou enzimática). O presente artigo objetivou relatar sobre os oligossacarídeos, enfatizando seus métodos de obtenção, algumas funções destes açúcares como fibras da dieta e suas atividades biológicas.

\section{Obtenção de oligossacarídeos por métodos físicos e químicos}

Os procedimentos físicos são os menos utilizados na produção e extração de oligossacarídeos funcionais por não apresentarem seletividade e não serem específicos. Um dos métodos recentes descritos na literatura é o uso de radiação de energia ionizante, até então utilizada como agente de ligação (cross-linking) entre polímeros artificiais (AL-ASSAF; PHILLIPS; WILLIAMS 2006).

Os métodos mais comuns envolvem mudanças drásticas de $\mathrm{pH}$ e temperatura, uso de microondas ou ultrasonicação (BEKERS et al., 2005). Zhang et al. (2005) obtiveram misturas oligossacarídicas de diferentes massas moleculares mantendo a estrutura química e conformação nativa da esquizofilana, uma $\beta$ - $(1 \rightarrow 3 ; 1 \rightarrow 6)$-glucana produzida pelo fungo Schizophyllum commune, através da degradação por irradiação ultra-sônica de alta energia.

A ultrasonicação e o uso de microondas em $\mathrm{pH} 1,5$ provocaram a hidrólise da xilana extraída 
de sementes de tamarindo, resultando em xilooligossacarídeos (VODENICAROVÁ et al., 2006). $\mathrm{O}$ tratamento com microondas também foi utilizado na obtenção de malto-oligossacarídeos a partir de hidrólise ácida de amilose, substituindo a etapa convencional de tratamento térmico (WARRAND; JANSSEN, 2007). Atualmente, estudos sobre a obtenção de celo-, malto- e xilo-oligossacarídeos através de processos físicos de colisão utilizando ciclotrons (FT-ICR) e quadrupolos elétricos (QIT) também têm sido investigados (PASANEN; JÄNIS; VAINIOTALO, 2007).

Dentre os procedimentos químicos utilizados na síntese de oligossacarídeos, se destacam as reações de condensação e hidrólise ácida. Porém, o primeiro método apresenta alguns inconvenientes e as etapas requeridas para a separação e purificação dos produtos são caras e apresentam baixo rendimento.

A síntese orgânica pode ocorrer também na presença de catalisadores como o composto trimetilsililtrifluormetanossulfonato (TMSOTf) e a partir de aceptores 4,6-O-benzilidenoglucopiranosil, os quais têm sido bastante utilizados na formação das ligações glicosídicas tipo $\beta-(1 \rightarrow 3)$ que são compostos com estrutura química correspondente à de exopolissacarídeos como a esquizofilana, epiglucana e lentinana (HE; YANG; DU, 2002).

As reações de hidrólise ácida usadas para a obtenção de oligossacarídeos devem ser controladas em termos de concentração de ácido, tipos de ácidos empregados e tempo de hidrólise. Um dos inconvenientes pode ser a formação de produtos colaterais como furfural, quando estão presentes pentoses, ou hidroximetil-furfural, quando as hexoses fazem parte da composição de polissacarídeos (AKPINAR; ERDOGAN; BOSTANCI, 2009).

Ahidróliseácida parcial se caracterizou como uma técnica útil na análise estrutural dos polissacarídeos (VESSELS; RADDING, 1993). Essas moléculas são quebradas de forma randômica gerando uma mistura de oligossacarídeos que uma vez isolados e quimicamente caracterizados auxiliam, pela superposição de seus fragmentos, na dedução da estrutura da macromolécula, tais como seqüência de resíduos e ligações glicosídicas (PAZUR, 1994). Em anos mais recentes verificou-se que muitos oligossacarídeos, principalmente aqueles com seis ou mais unidades monossacarídicas, conservam ou até mesmo potencializam as propriedades biológicas apresentadas por seus polissacarídeos. Uma possível explicação para essa constatação é a maior solubilidade dos oligossacarídeos, uma menor massa molecular e a manutenção da conformação quando comparados às suas moléculas nativas (BLAND; KESHAVARZ; BUCKE, 2004).

Diferentemente da especificidade da hidrólise enzimática, a hidrólise ácida parcial, que é um processo de degradação não seletivo, gera oligossacarídeos de diferentes tamanhos (SCHMID et al, 2001). Apesar disso, uma vantagem da hidrólise ácida está na possibilidade de ser realizada em temperaturas elevadas, promovendo maior fluidez das amostras submetidas a essa condição (SILVA et al., 2008).

A velocidade da hidrólise ácida total ou parcial de um polissacarídeo não é uniforme, visto que é afetada por alguns fatores como a configuração anomérica das ligações glicosídicas, tamanho do anel hemiacetálico, conformação dos monossacarídeos, natureza das ligações glicosídicas, presença de grupos funcionais e intensidade das interações inter e intramoleculares. As formas furanosídicas são mais facilmente hidrolisadas em condições mais suaves do que as piranosídicas; pentapiranosídeos hidrolizam-se mais rapidamente do que os hexapiranosídeos e as ligações glicosídicas $(1 \rightarrow 6)$ são mais resistentes à hidrólise do que ligações $(1 \rightarrow 4)$, que por sua vez são mais resistentes do que $(1 \rightarrow 3)$ e estas mais resistentes do que $(1 \rightarrow 2)$ (BIERMANN, 1988; CORRADI DA SILVA et al., 2006).

Se por um lado esse comportamento 
heterogêneo dos açúcares frente à hidrólise ácida total é desvantajoso, para a hidrólise ácida parcial é extremamente valioso, pois diferentes condições de reação podem gerar fragmentos diferentes que auxiliam na determinação da estrutura macromolecular (CORRADI DA SILVA et al., 2005). Portanto, se a reação for controlada por curvas de hidrólise apropriadas, selecionando-se o tipo de ácido, tempo e temperatura de reação haverá geração de fragmentos de diferentes massas moleculares, que poderão ser separados por procedimentos cromatográficos como filtração em gel, troca-iônica, carvão-Celite e outros (CORRADI DA SILVA et al., 2005), sendo que o uso de eletroforese capilar também vem se destacando (GONÇALVES et al., 2005).

Uma curva de hidrólise apropriada pode indicar o momento que a despolimerização deve ser interrompida e as condições devem ser controladas de modo a reduzir, ao mínimo, a destruição dos açúcares, ou mesmo impedir a re-polimerização dos fragmentos pela reversão ácida, com a conseqüente formação de produtos indesejáveis (BIERMANN, 1988).

Os ácidos mais utilizados na hidrólise são sulfúrico, clorídrico e trifluoracético (JOHANSSON et al, 2006). A fragmentação parcial de um polímero original pode ser efetuada com ácido trifluoracético. A vantagem na utilização deste ácido deve-se à sua remoção por evaporação sob pressão reduzida e à eliminação da etapa de neutralização por carbonato de bário, necessária quando o ácido sulfúrico é utilizado como catalizador da hidrólise (UKAI et al., 1982).

Segundo Johansson et al. (2006) fragmentos de oligossacarídeos com ligações $\beta-(1 \rightarrow 3)$, alternados por ligações $\beta-(1 \rightarrow 4)$ podem ser obtidos a partir dos polímeros originais, geralmente $\beta$-glucanas extraídas de cereais como aveia e cevada, a partir de hidrólise ácida em temperaturas elevadas. A extração de xilo-oligossacarídeos de xilana de semente de algodão foi realizada com ácido sulfúrico $(0,125 \mathrm{M})$ a $90^{\circ} \mathrm{C}$ (SUN et al., 2002).

A produção de oligossacarídeos a partir de polissacarídeos também é uma ferramenta essencial para determinar o padrão complexo de substituição mostrado por diversas galactanas, por exemplo. A hidrólise ácida parcial, desenvolvida na presença do complexo borano-4-metil morfolina, um agente redutor ácido estável, tem sido usada de forma eficiente na obtenção de oligossacarídeos a partir das galactanas. Este procedimento (hidrólise redutiva parcial) permite uma quebra seletiva das ligações 3,6-anidro galactopiranosídicas, enquanto grupos sulfato são retidos substancialmente (GONÇALVES et.al., 2002).

Um oligossacarídeo, caracterizado como gentiohexaose, foi obtido através da hidrólise ácida parcial da botriosferana, uma $\beta-(1 \rightarrow 3$; $1 \rightarrow 6$ )-glucana extracelular produzida pelo fungo ascomiceto Botryosphaeria rhodina. A hidrólise foi realizada com a presença de ácido trifluoracético $0,2 \mathrm{M}$ à $100^{\circ} \mathrm{C}$ durante 4 horas (SILVA et al., 2008).

A despolimerização de polissacarídeos através do processo Fenton é uma alternativa à hidrólise ácida, porém a síntese de oligossacarídeos através deste método não é controlada. Neste método, a presença de íons cobre complexados com polissacarídeos favorecem a formação de radicais hidróxi $(\mathrm{OH} \cdot)$, sendo que estas espécies reativas podem atuar sobre os polissacarídeos causando a despolimerização. Esta reação ocorre naturalmente em paredes celulares de plantas e tem sido utilizada in vitro para obtenção de fragmentos polissacarídicos (MCDOUGALL; FRY, 1991; BARRETEAU; DELATTRE; MICHAUD, 2006).

\section{Obtenção de oligossacarídeos por métodos enzimáticos}

O uso de enzimas para modificar estes exopolissacarídeos e ampliar seu potencial de aplicação biotecnológica, tem representado uma alternativa devido à alta especificidade destas 
proteínas em relação aos seus substratos. Dentre as reações enzimáticas utilizadas na obtenção de oligossacarídeos tem se destacado as reações de hidrólise, transglicosilação e isomerização.

As hidrolases são enzimas que catalisam a hidrólise de ligações glicosídicas e possuem ampla aplicação na indústria de alimentos constituindo uma ferramenta fundamental para a hidrólise de polissacarídeos ou oligossacarídeos (CRIMMINS; TABET, 2001). Apesar da alta especificidade sua aplicação ainda tem sido restrita, devido ao baixo rendimento. Entretanto, este constitui um problema que pode ser resolvido através do reciclo do substrato não utilizado na reação (MAITIN; RASTALL, 2004).

As reações de hidrólise enzimática consistem na remoção de prótons das moléculas de água para formar moléculas de oligossacarídeos e íons hidróxidos a partir de um polímero, tais como o amido ou a xilana, pela ação catalítica de enzimas hidrolases. Aação destas enzimas é classificada como exo-, quando atua a partir da extremidade terminal não-redutora; e endo-, constituindo uma ação hidrolítica randômica sobre o substrato, produzindo mono-, di- e oligossacarídeos (VANDAMME; SOETAERT, 1995; RAMESH; THARANATHAN, 2003).

Dentre as hidrolases mais utilizadas na produção de oligossacarídeos não-celulolíticos se destacam as amilases, glucanases e inulinases. As $\alpha$-amilases (EC 3.3.1.1; $\alpha-1 \rightarrow 4$ glicano 4-glicanohidroxilase) produzidas por diferentes cepas de Bacillus subtilis têm sido extensivamente utilizadas na obtenção de malto-oligossacarídeos por $\alpha$-amilase a partir de amido presente no bagaço-de-cana (KIMURA, 2000; NAGARAJAN; RAJAGOPALAN; KRISHNAN, 2006).

As exo-inulinases (EC 3.2.1.80; $\beta$-Dfrutopiranosídeo frutohidrolase) clivam ligações frutofuranosídicas seqüenciais a partir de ligações do tipo $\beta-(2 \rightarrow 1)$, e as endo-inulinases (EC 3.2.1.7; $\beta$-D-frutano frutanohidrolase) hidrolisam as ligações internas da inulina (polissacarídeo da frutose com uma unidade de glicose terminal) produzindo uma série de fruto-oligossacarídeos (KULMINSKAYA et al., 2003; CHENG; DUAN; SHEU, 2005).

A obtenção de gluco-oligossacarídeos a partir de $\beta$ - $(1 \rightarrow 3)$-glucanas foi realizada através da ação de $\beta$-1,3-glucanases fúngicas (GIESE et al., 2006; GRANDPIERRE et al., 2008; GIESE et al., 2009). Além de serem utilizadas na obtenção de oligossacarídeos, as reações de hidrólise enzimática de $\beta$-glucanas também auxiliam na caracterização estrutural, na determinação de suas propriedades reológicas e farmacológicas e de seus fragmentos (GIESE; CORRADI DA SILVA; BARBOSA, 2003).

Outro tipo de hidrólise que apresenta grande potencial biotecnológico é a hidrólise enzimática de resíduos agrícolas. Através da ação de xilanases, xilo-oligossacarídeos podem ser obtidos a partir de espigas de milho (MOURA et al., 2007). Subprodutos da agroindústria, tais como derivados da mandioca e da cana, também tem sido utilizados para este fim (RAUPP et al., 2002).

A síntese catalisada por enzimas representa uma alternativa interessante aos métodos químicos clássicos por permitir o controle da regioseletividade e da estereoquímica dos produtos finais de reação (PERUGINO et al., 2004). Este processo envolve duas classes de enzimas, as glicosidases e as glicosil transferases e tem contribuído para a obtenção de oligossacarídeos difíceis de serem produzidos pelos métodos convencionais de despolimerização e hidrólise enzimática (MONSAN; PAUL, 1995; SHODA; FUJITA; KOBAYASHI, 1998).

As glicosil transferases participam tanto de reações de transferência intramolecular como de transferência intermolecular. Estas enzimas são produzidas por fungos, leveduras e bactérias e são utilizadas como biocatalisadores livres ou imobilizados, sendo que paredes celulares de leveduras como $S$. cerevisiae e $P$. pastoris também têm sido utilizadas como fontes de enzima (ABE; 
SHIMMA; JIGAMI, 2003; WATANABE et al., 2006).

As glicosidases ocorrem em todos os seres vivos e catalizam a clivagem hidrolítica de resíduos terminais de D-glicosil em polissacarídeos e glicoproteínas, bem como em seus derivados (REZENDE; GUIMARÃES, 2004). Nos microrganismos, as glicosidases fazem parte de um complexo enzimático de degradação da celulose, responsável pela hidrólise da celobiose e de outros oligossacarídeos pequenos utilizados como fonte de energia em processos de fitopatogenicidade (NAKKHARAT; HALTRICH, 2006).

Estas enzimas também podem atuar na síntese de ligações glicosídicas in vitro, em condições de reação de hidrólise reversa, sob condições termodinamicamente controladas em alta temperatura ou cineticamente controladas na presença de açúcares nucleotídeos ativados (DAVIES; CHARNOCK; HENRISSAT, 2001).

No primeiro caso, as reações requerem ainda concentrações elevadas de substrato e baixa atividade de água para a síntese imediata do produto (LIESHOUT et al., 2004; GAUR et al., 2006). Nas reações sob controle cinético há a formação de um composto intermediário enzima-doador glicosil, o qual é então retido pelos grupos nucleofílicos para o alongamento da cadeia do oligossacarídeo (BHATIA; MISHRA; BISARIA, 2002).

Estas reações de condensação são de simples execução e, se a enzima for escolhida corretamente, pode apresentar seletividade absoluta (AJISAKA; YAMAMOTO, 2002; MAITIN; RASTALL, 2004). A regioseletividade destas reações pode ser controlada variando-se a fonte de enzima, sistema de solvente e a estrutura do aceptor glicosídeo (MURATA; USUI, 2000).

Os fruto-oligossacarídeos (FOs) podem ser obtido a partir da transfrutosilação da sacarose pela ação de $\beta$-frutosilfuranosidases (PASSOS; PARK, 2003). A levedura Scwhanniomyces occidentalis, por exemplo, é produtora de uma enzima $\beta$-frutofuranosidase capaz de atuar sobre a sacarose para produzir 6-cestose, um oligossacarídeo constituído por moléculas de frutose unidas por ligações glicosídicas do tipo $\beta-(2 \rightarrow 6)$ (ÁLVAROBENITO et al., 2007). Os FOs podem ser obtidos industrialmente por ação de $\beta$-frutosilfuranosidases de Aspergillus niger sobre a beterraba (RIVEROURGELL; SANTAMARIA-ORLEANS, 2001).

Os transgalacto-oligossacarídeos (TGOs) são obtidos através da transgalactosilação da lactose por ação das $\beta$-galactosidases. Os produtos finais desta reação apresentam uma grande variabilidade de ligações glicosídicas entre os monômeros de galactose e o terminal redutor de glucose, como as ligações $\beta-(1 \rightarrow 2)$; $\beta$ - $(1 \rightarrow 3)$ e $\beta$ - $(1 \rightarrow 4)$; além da ocorrência de ramificações com resíduos de glucose ao longo da cadeia. Estas características estruturais são importantes, pois implica na baixa resistência à acidez gástrica (BARRETEAU; DELATTRE; MICHAUD, 2006).

As $\beta$-galactosidases também catalisam reações de transgalactosilação que apresentam como produto final galacto-oligossacarídeos (GOs), atuando na hidrólise da lactose e síntese do oligossacarídeo a partir do mesmo substrato (RABIU et al., 2001; TZORTZIS et al., 2005). O rendimento e algumas reações de transgalactosilação foi em torno de 70 \% (LEE et al., 1997).

A produção de isomalto-oligossacarídeos, como a panose, envolve reações de transglicosilação catalisadas por $\alpha$-glicosidases utilizando amido como substrato. $\mathrm{O}$ rendimento da produção destes açúcares pela ação da $\alpha$-glicosidase de Xantophyllomyces dendrohous sobre a maltose foi 47 \% (FERNANDÉZ-ARROJO et al., 2007).

A síntese de laminari-oligossacarídeos através de transglicosilação com $\beta$-glucosidases também tem sido descrita. $\beta$ - $(1 \rightarrow 6 ; 1 \rightarrow 3)$-glucooligossacarídeos foram sintetizados a partir de celobiose utilizando-se duas preparações diferentes de $\beta$-glucosidases, uma de Sclerotinia sclerotiorum e outra de Aspergillus niger. Dentre os produtos 
de reação obtidos, o trissacarídeo $\beta$-Glc- $(1 \rightarrow 6)-\beta$ Glc- $(1 \rightarrow 3)-$ Glc foi sintetizado preferencialmente pela $\beta$-glucosidase de $S$. sclerotiorum (KAWAI et al., 2004; SMAALI et al., 2004). Os gentiooligossacarídeos foram obtidos através de reações de transglicosilação com $\beta$-glucosidases fúngicas a partir de uma alta concentração de glucose (UNNO et al., 2005; SANZ et al., 2006).

Através das reações de transglicosilação, alquil$\beta$-xilosídeos e xilobiosídeos têm sido obtidos na presença de xilana e álcoois, sendo que os álcoois primários são melhores aceptores para este tipo de reação. Jiang et al. (2004), utilizaram uma xilanase produzida por Thermotoga maritima MSB8 e obtiveram rendimentos de $33 \%$ em alquil- $\beta$ xilosídeos e $50 \%$ em xilobiosídeos como produtos finais da reação.

A endo- $\beta-(1,4)$-glucanase produzida por $A$. niger participa da reação de transferência de resíduos de celo-oligossacarídicos para moléculas de 1-octanol na presença de celopentaose como oligossacarídeo doador, dando origem a 1-octil-celotriosídeo (AKIBA; YAMAMOTO; KUMAGAI, 1999). A exo-(1,5)- $\alpha$-L-arabinanase produzida por $P$. chrysogenum quando na presença de grupos aceptores como álcoois alifáticos e alguns açúcares, apresentou atividade de trans-arabinosilação e sendo o glicerol foi um aceptor melhor para a formação de derivados arabino-oligossacarídicos (SAKAMOTO; FUJITA; KAWASAKI, 2004).

Estas reações também foram utilizadas como ferramenta na obtenção de polissacarídeos, como o caso da amilase de Dictyoglomus thermophilum que atuou sobre malto-oligossacarídeos e cicloamiloses e produziu uma cadeia de amilose de aproximadamente $200 \mathrm{kDa}$ (NAKAJIMA et al., 2004).

O rendimento das reações catalisadas por glicosidases é baixo devido à possibilidade de reversão da reação, que promove não somente a glicosilação, como também a hidrólise dos produtos formados (SHODA; FUJITA; KOBAYASHI,
1998). Assim, uma nova alternativa de síntese de oligossacarídeos é o envolvimento de glicosil hidrolases mutantes que apresentam um aminoácido não-nucleofílico no sítio catalítico, em substituição ao aminoácido nucleofílico presente no sítio ativo das glicosidases (JAKEMAN; WITHERS, 2002).

Estas enzimas, denominadas glicosintases, catalisam eficientemente a condensação de monossacarídeos, mas não apresentam atividade hidrolítica. Possuem também regioseletividade e estereoseletividade e podem ser facilmente obtidas, sendo amplamente utilizadas na produção de oligossacarídeos em escala industrial (MORACCI; TRINCONE; ROSSI, 2001; KOIZUMI, 2003; KIM; PARK; OH, 2005).

Como exemplos de reações catalisadas pelas glicosiltransferases se destacam a produção de ciclomaltopentaose com ligações $\alpha-(1 \rightarrow 6)$ a partir da glucanotransferase produzida por Bacillus circulans e a obtenção de fruto-oligossacarídeos pela ação da frutosiltransferase sobre a sacarose (WATANABE et al., 2006; GHAZI et al., 2006).

\section{Funções dos oligossacarídeos na dieta}

Os oligossacarídeos vêm sendo utilizados comercialmente como ingredientes de cosméticos, medicamentos, produtos agrícolas e principalmente na indústria alimentícia (CANO et al., 2006; KIYOHARA et al., 2006). Estes compostos são muitas vezes substituintes do açúcar atuando como adoçantes em alimentos de baixa caloria, e também são adicionados em sucos e refrigerantes para melhorar suas propriedades organolépticas (OKU; NAKAMURA, 2002). Também atuam como agentes anti-higroscópicos e umectantes, protegendo os alimentos da perda de água (LEE et al., 2004).

Recentemente, o desenvolvimento de novos alimentos/ingredientes alimentares funcionais impulsionou o estudo e a utilização de novos processos biotecnológicos na obtenção de 
oligossacarídeos visto que a procura vem aumentando gradativamente, devido suas propriedades peculiares (MOURE et al., 2006).

O termo "fibra da dieta" é utilizado para denominar as substâncias presentes nos alimentos que são resistentes às enzimas e que atuam no sistema digestivo (PHILLIPS; OGASAWARA; USHIDA, 2008). As fibras são importantes, pois auxiliam o bom funcionamento do sistema digestivo e evita o aparecimento de doenças como a síndrome de intestino curto, que consiste de um estado mal absortivo, bastante comum, após grandes ressecções intestinais (NONINO et al., 2001; MACHADO; SICHIERI, 2002).

A mudança dos hábitos alimentares, principalmente pela população brasileira, tem sido relacionada ao crescente aparecimento de doenças crônicas como a obesidade, aterosclerose, hipertensão, osteoporose e até mesmo alguns tipos de carcinomas. Pesquisas recentes demonstraram que o Diabetes mellitus também está relacionado ao baixo consumo de fibras alimentares pela população adulta no Brasil (MATTOS; MARTINS, 2000).

A promoção da qualidade de vida desde a infância tem servido como apelo das indústrias alimentícias no desenvolvimento e comércio de novos produtos, em função do atual consumo de dietas ricas em gordura e pobres em fibras, entre as crianças e adolescentes (NEUTZLING et al., 2007; VITOLO; CAMPAGNOLO; GAMA, 2007). $\mathrm{O}$ uso de aditivos como os oligossacarídeos em alimentos, preferidos por esta faixa etária, como bolos (MOSCATTO; PRUDÊNCIO-FERREIRA; HAULY, 2004), bebidas lácteas (THAMER; PENNA, 2006), iogurtes de soja (FUCHS et al., 2005; HAULY et al., 2005) são uma alternativa para suprir estas necessidades.

Os prebióticos são constituídos por carboidratos complexos, considerados oligossacarídeos não digeríveis, resistentes às ações de enzimas salivares e intestinais. São ingredientes nutricionais que afetam beneficamente o hospedeiro, estimulando seletivamente o crescimento e a atividade de uma ou mais bactérias intestinais benéficas, melhorando a saúde do hospedeiro (ANJO, 2004). Estimulam a proliferação de bactérias intestinais, que produzem ácidos orgânicos e contribuem para a diminuição do $\mathrm{pH}$. Também apresentam benefícios à saúde pela sua atividade antiadesiva, visto que inibem infecções por patógenos entéricos impedindo a adesão destes às células epiteliais gastrointestinais (HOLZAPFEL; SCHILLINGER, 2002; SHOAF et al., 2006). Estudos sobre os efeitos antiinflamatórios de prebióticos em inflamações do intestino, diminuição dos níveis de glucose no sangue, assim como dos níveis de colesterol sérico também têm sido relatados (TOSH et al., 2004; LARAVILLOSLADA et al., 2006).

Os microrganismos intestinais viáveis que afetam beneficamente a saúde e proporcionam um balanço da flora microbiana intestinal, são denominados probióticos. Os mais empregados são bactérias, leveduras e bifidobactérias, as que são utilizadas para prevenir ou tratar diversas disfunções gastrintestinais, tais como a intolerância à lactose, constipação, hipersensibilidade alimentar e gastrenterites (COPPOLA; TURNES, 2004).

Pesquisas recentes têm demonstrado os efeitos benéficos dos probióticos sobre o equilíbrio bacteriano intestinal, controle do colesterol e de diarréias. As bactérias probióticas atuam produzindo vitaminas, viabilizando a absorção de minerais e elementos traços, produzindo importantes enzimas digestivas, como as $\beta$-galactosidases, entre outros (HOLZAPFEL; SCHILLINGER, 2002; RAMESH; THARANATHAN, 2003).

Portanto, a presença de bifidobactérias e lactobacilos constituem um critério de indicação de boa saúde por constituírem parte da microflora, sendo importante a ingestão de prebióticos para a sua manutenção. Também auxiliam na proteção contra infecções e alergias durante a infância (BRUZZESE et al., 2006). Os fruto-oligossacarídeos (FOs) são considerados os principais oligossacarídeos 
com ação prebiótica, sendo adicionados a vários produtos, tais como biscoitos, bebidas, iogurtes, cereais matinais, geléias e doces (ROBERFROID, 2002).

Os FOs promovem seletivamente o crescimento de Acidophillus, Bifidus e Faecium, que são bactérias benéficas do trato gastrintestinal (CAMPBELL; FAHEY; WOLF, 1997; PASSOS; PARK, 2003). Ao estimular a flora intestinal, os FOs contribuem para o aumento da produção de ácidos orgânicos e inibem a proliferação de patógenos sensíveis a estas condições (TEN BRUGGENCATE et al., 2003).

O equilíbrio produzido na flora gastrintestinal é responsável por outros benefícios ao metabolismo humano, como a redução da pressão sanguínea em pessoas hipertensas, alteração do metabolismo de ácidos gástricos, redução da absorção de carboidratos e lipídeos, normalizando a pressão sanguínea e lipídeos séricos, melhorando o metabolismo de diabéticos (ZAFAR et al., 2004; DUCROS et al., 2005; BARRETEAU; DELATTRE; MICHAUD, 2006).

Os xilo-oligossacarídeos (XOs) também atuam como prebióticos, diminuem os níveis de açúcares no sangue e o metabolismo das gorduras (MONSAN; PAUL, 1995; ALONSO et al., 2003). Outros oligossacarídeos, como a lactosacarose, os isomaltooligossacarídeos (IMOs), galacto-oligossacarídeos (GOs), transgalacto-oligossacarídeos (TGOs), rafinose, estaquiose também têm recebido atenção, visto que podem atuar como fatores de crescimento para bifidobactérias e são utilizados em vários alimentos (ONISHI; TANAKA, 1998; OKU; URA, 2003; ALMEIDA; PASTORE, 2004; YAMASHITA et al., 2005).

Os gentio-oligossacarídeos apresentam atividade bifidogênica (RYCROFT et al., 2001). Estudos recentes demonstraram que gentio-oligossacarídeos com grau de polimerização (GP) de 2 a 3 unidades glicosídicas, apresentaram melhor resposta como fator de crescimento para as bifidobactérias, que os que apresentavam GP igual a 4 e 5 (SANZ et al.,
2006). Por sua vez, os laminari-oligossacarídeos também são capazes de estimular a proliferação de bifidobactérias do ceco (primeira porção do intestino grosso) (SALYERS; PALMER; WILKINS, 1977).

A geração de gases pela microflora intestinal e o mal-estar algumas vezes causado pela ingestão de alimentos contendo prebióticos e probióticos, tende a ser minimizados pelo estudo da ação sinérgica de misturas de oligossacarídeos que parecem diminuir estes efeitos (GHODDUSI et al., 2007).

$\mathrm{O}$ número de bifidobactérias no intestino de crianças amamentadas pela mãe é consideravelmente mais saudável, do que os encontrados nos alimentos destinados à crianças em lactação. O leite humano contém oligossacarídeos que promovem a proliferação de determinadas espécies de bifidobactérias. Nos últimos anos, a procura de uma fórmula ideal de probióticos e prebióticos em alimentos para crianças na fase de lactação tem sido crescente (PUCCIO et al., 2007).

\section{Atividades biológicas dos oligossacarídeos}

O conceito de alimento funcional surgiu no Japão, e foi regulamentado em 1991, tendo recebido a denominação "Foods for Specified Health Use" (FOSHU). Segundo a ANVISA, alimentos funcionais são aqueles que produzem efeitos metabólicos ou fisiológicos, através da atuação de um nutriente ou não nutriente no crescimento, desenvolvimento, manutenção e em outras funções normais do organismo humano.

Definidos como produtos, os alimentos funcionais contêm em sua composição algumas substâncias biologicamente ativas, que ao serem adicionados à uma dieta usual, desencadeiam processos metabólicos ou fisiológicos, resultando na redução do risco de doenças e manutenção da saúde (NAGARAJAN; RAJAGOPALAN; KRISHNAN, 2006).

A adição de fibras nestes alimentos deve ser monitorada, para que ao serem ingeridas, não 
arrastem os nutrientes da dieta tais como lipídeos, minerais, proteínas e carboidratos digeríveis, para as fezes (RAUPP et al., 2002). Os produtos destinados à infância são especialmente controlados, uma vez que metabólitos como o colesterol é essencial para o metabolismo infantil, e alguns oligossacarídeos são utilizados como aditivos alimentares por apresentam ação hipocolesterolêmica (ALLIET et al., 2007).

Os fruto-oligossacarídeos (FOs) aumentam a absorção de cobre, cálcio, magnésio e ferro (ZAFAR et al., 2004; DUCROS et al., 2005; BARRETEAU; DELATTRE; MICHAUD, 2006; OHTA, 2006; BORYCKA; STACHOWIAK, 2008). Também apresentam um efeito positivo no tratamento de hiperplasia no ceco (NZEUSSEU et al., 2006). As propriedades funcionais dos oligossacarídeos estão diretamente relacionadas com a estrutura tridimensional, a qual é responsável por interações com outras biomoléculas (ALMOND 2005; ALASSAF; PHILLIPS; WILLIAMS, 2006).

Os oligossacarídeos têm sido extensivamente utilizados por suas propriedades reológicas como espessantes em emulsões de glucose, aminoácidos e lipídios, administrados por via intravenosa, em pacientes pós-cirúrgicos (STEGINK et al., 1987). Também têm sido estudados na formulação de medicamentos que apresentam liberação controlada de princípios ativos, como agentes carreadores, por apresentarem resistência à ação de glicosidases e outras hidrolases que existem nos organismos (YUASA; HASHIMOTO, 2001; COVIELLO et al., 2005). Estes medicamentos apresentam vantagens sobre as terapias convencionais, as quais podem ser tóxicas por requererem uma alta quantidade do princípio ativo, ou até mesmo serem inefetivas (LANGER, 1995).

Os oligossacarídeos, tanto as ciclodextrinas como os que apresentam conformação em hélice tripla, podem ser utilizados como carreadores de pequenas moléculas como proteínas, peptídeos e ácidos nucléicos. Estas nanopartículas servem como proteção, transporte e entrega das drogas e, uma vez reconhecidas, são rapidamente eliminadas do "bloodstream" após a administração intravenosa (LEMARCHAND et al., 2006).

Os gluco-oligossacarídeos bioativos derivados das $\beta$-( $(1 \rightarrow 3)$-glucanas estimulam a resposta antiinflamatória mediada pelas células do sistema imune, através da indução de mediadores pró- e antiinflamatórios, como a citocina, fator de necrose tumoral alfa (TNF- $\alpha$ ) e também a isoleucina-1 (IL-1), entre outras. $\mathrm{O}$ mecanismo de ação anti-tumoral tem sido relacionado à indução das diversas respostas imunológicas do hospedeiro, principalmente pela ativação das células "natural killer" (NK) (PANG et al., 2005).

Os gluco-oligossacarídeos têm sido descritos por apresentarem excelente atividade como agentes imunomoduladores (PANG et al., 2005). A laminaritetraose e laminaripentaose estimularam a atividade fagocítica de granulócitos e macrófagos responsáveis pela fagocitose de tecidos necrosados e pela estimulação das células do sistema imune (JAMOIS et al., 2005). Os oligossacarídeos derivados da curdlana, uma $\beta$-(1,3)-glucana linear, aumentaram a produção de TNF- $\alpha$ pelos macrófagos (KATAOKA et al., 2002). Por sua vez, Miyanishi et al. (2003) verificaram a atividade citotóxica em mielomas humanos quando utilizaram uma mistura oligossacarídica de $\mathrm{GP} \geq 4$ provenientes da hidrólise enzimática da laminarina.

O grau de polimerização dos glucooligossacarídeos também parece ser fundamental para sua aplicação farmacológica. A laminariheptose tem sido descrita por possuir atividade biológica distinta da laminarihexose devido à conformação espacial que a presença de uma molécula de glucose a mais confere ao oligossacarídeo, o que parece favorecer a sua interação com as células imunes humanas (LOWE et al., 2001; BLAND; KESHAVARZ, T.; BUCKE, 2004).

Oligossacarídeos que contêm ácidos e acetais pirúvicos são componentes de diversos fatores antigênicos bacterianos e são, conseqüentemente, 
alvos potenciais de estudos imunológicos e vacinas sintéticas (GONÇALVES et al., 2002; NABARLATZ et al., 2007). A introdução de grupos iônicos nestas moléculas não só aumentam a solubilidade em água como causam mudanças nas ligações intra- e intermoleculares de hidrogênio aumentando a repulsão entre as cadeias e mudando a sua conformação e suas atividades biológicas (ZHANG et al., 2003).

Pesquisas recentes relataram que as maltodextrinas reduziram em até $52 \%$ o câncer de cólon em ratos (VERGHESE et al., 2005). Por sua vez, os XOs têm sido descritos como mais eficientes no tratamento do câncer de cólon que os FOs (HSU et al., 2004).

\section{Considerações Finais}

Os oligossacarídeos constituem uma classe de biomoléculas ativas de grande importância para a saúde humana. Avanços da tecnologia utilizada nos processos de obtenção destes oligômeros são necessários para o desenvolvimento de produtos alimentícios funcionais. O uso de enzimas em detrimento aos processos químicos e físicos tem se tornado possível, através do uso da engenharia genética na seleção de novas linhagens microbianas mutantes, para a produção destes catalisadores. A conscientização e a adequação dos hábitos alimentares se fazem necessárias para que todos os benefícios destes carboidratos se façam presentes.

\section{Agradecimentos}

Os autores agradecem à Fundação de Amparo à Pesquisa do Estado de São Paulo (FAPESP) e Fundação Araucária do Paraná-Projeto No 5777 pelo auxílio financeiro. Ellen C. Giese agradece à FAPESP pela bolsa de doutorado concedida.

\section{Referências}

ABE, H.; SHIMMA, T-I.; JIGAMI, Y. In vitro oligosaccharide synthesis using intact yeast cells that display glycosyltransferases at the cell surface through cell wall-anchored protein Pir. Glycobiology, Oxford, v. 13, n. 2, p. 87-95, 2003.

AJISAKA, K; YAMAMOTO, Y. Control of the regioselectivity in the enzymatic syntheses of oligosaccharides using glycosidases. Trends in Glycoscience and Glycotechnology, Weinheim, v. 14, n. 45, p. 1-11, 2002.

AKIBA, S.; YAMAMOTO, K.; KUMAGAI, $\mathrm{H}$. Transglycosylation activity of the endo- $\beta$-1,4-glucanase from Aspergillus niger IFO31125 and its application. Journal of Bioscience and Bioenginering, Tokyo, v. 87, n. 5, p. 576-580, 1999.

AKPINAR, O.; ERDOGAN, K.; BOSTANCI, S. Production of xylooligosaccharides by controlled acid hydrolysis of lignocellulosic materials. Carbohydrate Research, Amsterdam, v. 344, n. 5, p. 660-666, 2009.

AL-ASSAF, S.; PHILLIPS, G. O.; WILLIAMS, P. A. Controlling the molecular structure of food hydrocolloids. Food Hydrocolloids, Oxford, v. 20, n. 2-3, p. 369-377, 2006.

ALLIET, P.; SCHOLTENS, P.; RAES, M.; HENSEN, K.; JONGEN, H.; RUMMENS, J.; BOEHM, G.; VANDENPLAS, Y. Effect of prebiotic galactooligosaccharide, long-chain fructo-oligosaccharide infant formula on serum cholesterol and triacylglycerol levels. Nutrition, New York, v. 23, n. 10, p. 719-723, 2007.

ALMEIDA, M. M.; PASTORE, G. M. Açúcares funcionais: Produção de galactooligossacarídeos por $\beta$-galactosidases utilizando metodologia de superfície de resposta. Biotecnologia Ciência e Desenvolvimento, Brasília, n. 32, jan./jun. p. 10-14, 2004.

ALMOND, A. Towards understanding the interaction between oligosaccharides and water molecules. Carbohydrate Research, Amsterdam, v. 340, n. 5, p. $907-$ 920, 2005.

ALONSO, J. L.; DOMÍNGUEZ, H.; GARROTE, G.; PARAJÓ, J. C.; VÁZQUEZ, M. J. Xylooligosaccharides: Properties and production technologies. Electronic Journal of Environmental, Agricultural and Food Chemistry, Ourense, v. 2, n. 1, p. 230-232, 2003.

ÁlVARO-BENITO, M.; ABREU, M.; FERNÁNDEZARROJO, L.; PLOU, F. J.; JIMÉNEZ-BARBERO, J.; BALLESTEROS, A.; POLAIN, J.; FERNÁNDEZLOBATO, M. Characterization of a $\beta$-fructofuranosidase from Schwanniomyces occidentalis with transfructosylating activity yielding the prebiotic 6-kestose. Journal of Biotechnology, Amsterdam, v. 132, n. 1, p. $75-81,2007$. 
ANJO, D. F. C. Alimentos funcionais em angiologia e cirurgia vascular. Jornal Vascular Brasileiro, Rio de Janeiro, v. 3, n. 2, p. 145-154, 2004.

BARRETEAU, H.; DELATTRE, C.; MiCHAUD, P. Production of oligosaccharides as promising new food additive generation. Food Technology and Biotechnology, Zagreb, v. 44, n. 3, p. 323-333, 2006.

BEKERS, M.; UPITE, D.; KAMINSKA, E.; LAUKEVICS, J.; GRUBE, M.; VIGANTS, A.; LINDE, R. Stability of levan produced by Zymomonas mobilis. Process Biochemistry, London, v. 40, n. 5, p. 1535-1539, 2005.

BHATIA, Y.; MISHRA, S.; BISARIA, V. S. Microbial $\beta$-glucosidases: cloning, properties and applications. Critical Reviews in Biotechnology, London, v. 22, n. 4, p. 375-407, 2002.

BIERMANN, C. Hydrolysis and other cleavages of glycosidic linkages in polysaccharides. Advances in Carbohydrate Chemistry and Biochemistry, San Diego, v. 46, n. 1, p. 251-271, 1988.

BLAND, E. J.; KESHAVARZ, T.; BUCKE, C. The influence of small oligosaccharides on the immune system. Carbohydrate Research, Amsterdam, v. 339, n. 10, p. 1673-1678, 2004.

BORYCKA, B.; STACHOWIAK, J. Relations between cadmium and magnesium and aronia fractional dietary fibre. Food Chemistry, Oxford, v. 107, n. 1, p. 44-48, 2008.

BRUZZESE, M.; VOLPICELLI, M.; SQUAGLIA, M.; TARTAGLIONE, A.; GUARINO, A. Impact of prebiotics on human health. Digestive and Liver Disease, New York, v. 38, n. 2, p. S283-287, 2006.

CAMPBELL, J. M.; FAHEY, G. C.; WOLF, B. W. Selected indigestible oligosaccharides affect large bowel mass, cecal and fecal short-chain fatty acids, $\mathrm{pH}$ and microflora in rats. The Journal of Nutrition, Bethesda, $\mathrm{v}$. 127, n. 1, p. 130-136, 1997.

CANO, A.; MOSCHOU, E. A.; DAUNERT, S.; COELLO, J.; PALET, C. Optimization of the xylan degradation activity of monolithic enzymatic membranes as a function of their composition using design of experiments. Bioprocess and Biosystems Engineering, New York, v. 29, n. 4, p. 261-268, 2006.

CHENG, T-C.; DUAN, K-J.; SHEU, D-C. Immobilization of $\beta$-fructofuranosidase from Aspergillus japonicus on chitosan using tris(hydroxymethyl)phosphine or glutaraldehyde as a coupling agent. Biotechnology Letters, Netherlands, v. 27, n. 5, p. 335-338, 2005.

COPPOLA, M. M.; TURNES, C. G. Probióticos e resposta imune. Ciência Rural, Santa Maria, v. 34, n. 4, p. 1297-1303, 2004.

CORRADI DA SILVA, M. L.; IZELI, N. L.; MARTINEZ, P. F.; SILVA, I. R.; CONSTANTINO, C. J. L.; CARDOSO, M. S.; BARBOSA, A. M.; DEKKER, R. F. H.; SILVA, G. V. J. Purification and structural characterisation of $(1,3 ; 1,6)$ beta-D-glucans (botryosphaerans) from Botryosphaeria rhodina MAMB-05 grown on sucrose and fructose as carbon sources: a comparative study. Carbohydrate Polymers, Barking, v. 61, n. 1, p. 10-17, 2005.

CORRADI DA SILVA, M. L.; MARTINEZ, P. F.; IZELI, N. L.; SILVA, I. R.; CARDOSO, M. S.; STELUTI, R. M.; GIESE, E. C.; BARBOSA, A. M. Caracterização química de glucanas fúngicas e suas aplicações tecnológicas. Química Nova, São Paulo, v. 29, n. 1, p. 85-92, 2006.

COVIELLO, T.; GRASSI, M.; PALLESCHI, A.; BOCCHINFUSO, G.; COLUZZI, G.; BANISHOEIB, F.; ALHAIQUE, F. A new scleroglucan/borax hydrogel: swelling and drug release studies. International Journal of Pharmaceutics, Netherlands, v. 289, n. 1-2, p. 95-107, 2005.

CRIMMINS, M. T.; TABET, E. Formal total synthesis of (-)-trehazolin via an asymmetric aldol-ring closing metathesis strategy. Journal of Organic Chemistry, Washington, v. 65, n. 11, p. 4012, 2001.

DAVIES, G. J.; CHARNOCK, S. J.; HENRISSAT, B. The enzymatic synthesis of glycosidic bonds: "Glycosynthases" and Glycosyltransferases. Trends in Glycoscience and Glycotechnology, Weinheim, v. 13, n. 7, p. 105-120, 2001.

DUCROS, V.; ARNAUD, J.; TAHIRI, M.; COUDRAY, C.; BORNET, F.; BOUTELOUP-DEMANGE, C.; BROUNS, F.; RAYSSIGUIER, Y.; ROUSSEL, A. M. Influence of short-chain fructo-oligosaccharides (sc-FOS) on absorption of $\mathrm{Cu}, \mathrm{Zn}$, and $\mathrm{Se}$ in healthy postmenopausal women. Journal of the American College of Nutrition, Clearwater, v. 24, n. 1, p. 30-37, 2005.

FERNÁNDEZ-ARROJO, L.; MARÍN, D.; SEGURA, A. G.; LINDE, D.; ALCALDE, M.; GUTIÉRREZALONSO, P.; GHAZI, I.; PLOU, F. J.; FERNÁNDEZLOBATO, M. ; BALLESTEROS, A. Transformation of maltose into prebiotic isomaltooligosaccharides by a novel $\alpha$-glucosidase from Xantophyllomyces dendrorhous. Process Biochemistry, London, v. 42, n. 11, p. 1530-1536, 2007.

FUCHS, R. H. B.; BORSATO, D.; BONA, E.; HAULY, M. C. O. "Iogurte" de soja suplementado com oligofrutose 
e inulina. Ciência e Tecnologia de Alimentos, Campinas, v. 25 , n. 1, p. 175-179, 2005.

GAUR, R.; PANT, H.; JAIN, R.; KHARE, S. K. Galactooligosaccharide synthesis by immobilized Aspergillus oryzae $\beta$-galactosidase. Food Chemistry, Oxford, v. 97, n. 3, p. 426-430, 2006.

GHAZI, I.; DE SEGURA, A. G.; FERNÁNDEZARROJO, L.; ALCALDE, M.; YATES, M.; ROJASCERVANTES, M. L.; PLOU, F. J.; BALLESTEROS, A. Immobilisation of fructosyltransferase from Aspergillus aculeatus on epoxy-activated Sepabeads EC for the synthesis of fructo-oligosaccharides. Journal of Molecular Catalysis B: Enzymatic, New York, v. 35, n. 1-3, p. 19-23, 2005.

GHODDUSI, H. B.; GRANDISON, M. A.; GRANDISON, A. S.; TUOHY, K. M. In vitro study on gas generation and prebiotic effects of some carbohydrates and their mixtures. Anaerobe, Oxford, v. 13, n. 5-6, p. $193,1997$.

GIESE, E. C.; CORRADI DA SILVA, M. L.; BARBOSA, A. M. Glucanases fúngicas: produção e aplicações das 及-1,3- e $\beta$-1,6-glucanases. Biotecnologia, Ciência e Desenvolvimento, Brasília, v. 30, jan./jun. p. 97-103, 2003.

GIESE, E. C.; COVIZZI, L. G.; DEKKER, R. F. H.; MONTEIRO, N.; K.; CORRADI DA SILVA, M. L.; BARBOSA, A. M. Enzymatic hydrolysis of botryosphaeran and laminarin by $\beta$-1,3-glucanases produced by Botryosphaeria rhodina and Trichoderma harzianum Rifai. Process Biochemistry, London, v. 41, n. 6, p. 1265-1271, 2006.

GIESE, E. C.; MONTEIRO, A. C.; BARBOSA, A. M.; DEKKER, R. F. H.; SANTOS JUNIOR, O. A.; CORRADI DA SILVA, M. L.; GOMES, E.; SILVA, R. Evaluation of the $\beta$-glucanolytic enzyme complex of Trichoderma harzianum Rifai for the production of glucooligosaccharide fragments by enzymatic hydrolysis of 1,3;1,6- $\beta$-D-glucans In: Current Research Topics in Applied Microbiology and Microbial Biotechnology : World Scientific Publishing Co. Pte. Ltd., 1, p. 438-441, 2009.

GONÇALVES, A. G.; DUCATTI, D. R. B.; PARANHA, R. G.; DUARTE, M. E. R.; NOSEDA, M. D. Positional isomers of sulfated oligosaccharides obtained from agarans and carrageenans: preparation and capillary electrophoresis separation. Carbohydrate Research, Amsterdam, v. 340, n. 23, p. 2123-2134, 2005.

GONÇALVES, A. G.; DUCATTI, D. R. B.; DUARTE, M. E. R.; NOSEDA, M. D. Sulfated and pyruvylated disaccharide alditols obtained from a red seaweed galactan: ESIMS and NMR approaches. Carbohydrate Research, London, v. 337, n. 24, p. 2443-2453, 2002.

GRANDPIERRE, C.; JANSSEN, H.G.; LAROCHE, C.; MICHAUD, P.; WARRAND, J. Enzymatic and chemical degradation of curdlan targeting the production of $b-(1,3)$ oligoglucans. Carbohydrate Polymers, London, v. 71, n. 2, p. 277-286, 2008.

HAULY, M. C. O.; FUCHS, R. H. B.; PRUDÊNCIOFERREIRA, S. H. Suplementação de iogurte de soja com frutooligossacarídeos: características probióticas e aceitabilidade. Revista de Nutrição, Campinas, v. 18, n. 5, p. 32-35, 2005.

HE, H.; YANG, F.; DU, Y. Synthesis of natural $\beta$-D$(1 \rightarrow 3)$-glucopyranosyl oligosaccharides. Carbohydrate Research, London, v. 337, n. 18, p. 1673-1678, 2002.

HIRAYAMA, M. Novel physiological functions of oligosaccharides. Pure and Applied Chemistry, Res Triangle PK, v. 74, n. 1-4, p. 1271, 2002.

HOLZAPFEL, W. H.; SCHILLINGER, U. Introduction to pre- and probiotics. Food Research International, Netherlands, v. 35, n. 2-3, p. 109-116, 2002.

HSU, C-K.; LIAO, J. W.; CHUNG, Y-C.; HSIEH, C-P.; CHAN, Y-C. Xylooligosaccharides and fructooligosaccharides affect the intestinal microbiota and precancerous colonic lesion development in rats. Journal of Nutrition, Bethesda, v. 134, n. 6, p. 1523$1528,2004$.

JAKEMAN, D. L.; WITHERS, S. G. Glycosynthases: new tools for oligosaccharide synthesis. Trends in Glycoscience and Glycotechnology, Weinheim, v. 14, n. 45, p. 13-25, 2002.

JAMOIS, F.; FERRIÈRES, V.; GUÉGAN, J-P.; YVIN, J-C.; PLUSQUELLEC, D.; VETVICKA, V. Glucan-like synthetic oligosaccharides: iterative synthesis of linear oligo- $\beta$-(1,3)-glucans and immunostimulatory effects. Glycobiology, Cary, v. 15, n. 4, p. 393-407, 2005.

JIANG, Z.; ZHU, Y.; LITE, L.; YU, X.; KUSAKABE, I.; KITAOKA, M.; HAYASHI, K. Transglycosylation reaction of xylanase $\mathrm{B}$ from the hyperthermophilic Thermotoga maritima with the ability of synthesis of tertiary alkyl $\beta$-D-xylobiosides and xylosides. Journal of Biotechnology, Netherlands, v. 114, n. 1-2, p. 125-134, 2004.

JOHANSSON, L.; VIRKKI, L.; ANTTILA, H.; ESSELSTRÖM, H.; TUOMAINEN, P.; SONTAGSTROHM, T. Hydrolysis of $\beta$-glucan. Food Chemistry, Oxford, v. 97, n. 1, p. 71-79, 2006.

KATAOKA, K.; MUTA, T.; YAMAZAKI, S.; TAKESHIGE, K. Activation of macrophages by linear 
(1,3)- $\beta$-D-glucans. The Journal of Biological Chemistry, New York, v. 277, n. 1, p. 36825-36831, 2002.

KAWAI, R.; IGARASHI, K.; KITAOKA, M.; ISHII, T.; SAMEJIMA, M. Kinetics of substrate transglycosylation by glycoside hydrolase family 3 glucan $(1,3)$ - $\beta$-glucosidase from the white-rot fungus Phanerochaete chrysosporium. Carbohydrate Research, London, v. 339, n. 18, p. 2851-2857, 2004.

KIM, Y-S.; PARK, C-S.; OH, D-K. Lactulose production from lactose and fructose by a thermostable-galactosidase from Sulfolobus solfataricus. Enzyme and Microbial Technology, New York, v. 39, n. 4, p. 903-908, 2006.

KIMURA, A. New horizons of carbohydrate bioengineering. molecular anatomy of $\alpha$-glucosidase. Trends in Glycoscience and Glycotechnology, Weinheim, v. 12 , n. 68 , p. 373-380, 2000.

KIYOHARA, M.; HAMA, Y.; YAMAGUCHI, K.; ITO, M. Structure of $\beta-1,3$-xylooligosaccharides generated from Caulerpa racemosa var. laete-virens $\beta-1,3$-xylan by the action of $\beta-1,3$-xylanase. Journal of Biochemistry, Oxford, v. 140, n. 3, p. 369-373, 2006.

KOIZUMI, S. Large-scale production of oligosaccharides using bacterial functions. Trends in Glycoscience and Glycotechnology, Weinheim, v. 15, n. 82, p. 65-74, 2003.

KULMINSKAYA, A. A.; ARAND, M.; ENEYSKAYA, E. V.; IVANEN, D. R.; SHABALIN, K. A.; SHISHLYANNIKOV, S. M.; SAVELIEV, A. N.; KORNEEVA, O. S.; NEUSTROEV, K. N. Biochemical characterization of Aspergillus awamori exoinulinase: substrate binding characteristics and regioselectivity of hydrolysis. Biochimica et Biophysica Acta, Amsterdam, v. 1650, n. 1-2, p. 22-29, 2003.

LANGER, R. Biomaterials and biomedical engineering. Annals of Biomedical Engineering, New York, v. 30, n. 24, p. 2-10, 1995.

LARA-VILLOSLADA, F.; HARO, O.; CAMUESCO, D.; COMALADA, M.; VELASCO, J.; ZARZUELO, A.; XAUS, J.; GALVEZ, J. Short-chain fructooligosaccharides, in spite of being fermented in the upper part of the large intestine, have anti-inflammatory activity in the TNBS model of colitis. European Journal of Nutrition, Heidelberg, v. 45, n. 7, p. 418-425, 2006.

LEE, C. Y., YUN, C. L.; YUN, J. W.; OH, T. K.; KIM, C. J. Production of glucooligosaccharides by an acceptor reaction using two types of glucansucrase from Streptococcus sobrinus. Biotechnology Letters, Netherlands, v. 19, n. 12, p. 1227-1230, 1997.

LEE, G.; NOWAK, N.; JARONIEC, J.; ZHANG, Q.; MARSZALEK, P. E. Molecular dynamics simulations of forced conformational transitions in 1,6-linked polysaccharides. Biophysical Journal, Cambridge, v. 87, n. 3, p. 1456-1465, 2004.

LEMARCHAND, C.; GREF, R.; PASSIRANI, C.; GARCION, E.; PETRI, B.; MÜLLER, R.; COSTANTINI, D.; COUVREUR, P. Influence of polysaccharide coating on the interactions of nanoparticles with biological systems. Biomaterials, Oxford, v. 27, n. 1, p. 108-118, 2006.

LIESHOUT, J. V.; FAIJES, M.; NIETO, J.; OOST, J.; PLANAS, A. Hydrolase and glycosynthase activity of endo-1,3- $\beta$-glucanase from the thermophile Pyrococcus furiosus. Archaea, Vancouver, v. 1, n. 4, p. 285-292, 2004.

LOWE, E., RICE, P.; TUANZHU, H. A.; CHUANFU, L. I.; KELLEY, J.; ENSLEY, H.; LOPEZ-PEREZ, J.; KALBFLEISCH，J.; LOWMAN，D.; MARGL，P.; BROWDER, W.; WILLIAMS, D. A (1,3)- $\beta$-D-linked heptasaccharide is the unit ligand for glucan pattern recognition receptors on human monocytes. Microbes and Infection, Netherlands, v. 3, n. 10, p. 789-797, 2001.

MACHADO, P. A. N.; SICHIERI, R. Relação cinturaquadril e fatores de dieta em adultos. Revista Saúde Pública, São Paulo, v. 36, n. 2, p. 29-33, 2002.

MAITIN, V.; RASTALL, R. A. Enzyme glycation influences product yields during oligosaccharide synthesis by reverse hydrolysis. Journal of Molecular Catalysis B: Enzymatic, New York, v. 30, n. 5-6, p. 195202, 2004.

MATTOS, L. L.; MARTINS, I. S. Consumo de fibras alimentares em população adulta. Revista Saúde Pública, São Paulo, v. 34, n. 1, p. 13-16, 2000.

MCDOUGALL, J. G.; FRY, S. C. Purification and analysis of growth-regulating xyloglucan-derived oligosaccharides by high-pressure liquid chromatography. Carbohydrate Research, London, v. 219, n. 14, p. 123 132, 1991.

MIYANISHI, N.; IWAMOTO, Y.; WATANABE, E.; ODA, T. Induction of TNF- $\alpha$ production from human peripheral blood monocytes with $\beta$-1,3-glucan oligomer prepared from laminarin with $\beta$-1,3-glucanase from Bacillus clausii NM-1. Journal of Bioscience and Bioengineering, Osaka, v. 95, n. 2, p. 192-195, 2003.

MONSAN, P.; PAUL, F. Enzymatic synthesis of oligosaccharides. FEMS Microbiology Reviews, Malden, v. 16, n. 5, p. 187-192, 1995.

MORACCI, M.; TRINCONE, A.; ROSSI, M. Glycosynthases: new enzymes for oligosaccharide synthesis. Journal of Molecular Catalysis B: Enzymatic, New York, v. 11, n. 4-6, p. 155-163, 2001. 
MOSCATTO, J. A.; PRUDÊNCIO-FERREIRA, S. H.; HAULY, M. C. O. Farinha de yacon e inulina como ingredientes na formulação de bolo de chocolate. Ciência e Tecnologia de Alimentos, Campinas, v. 24, n. 4, p. 634639, 2004.

MOURA, P.; BARATA, R.; CARVALHEIRO, F.; GIRIO, F.; LOUREIRO-DIAS, M.; ESTEVES, M. P. In vitro fermentation of xylo-oligosaccharides from corn cobs autohydrolysis by Bifidobacterium and Lactobacillus strains. LWT Food Science Technology, Oxford, v. 40, n. 6, p. 963-972, 2007.

MOURE, A; GULLÓN, P.; DOMÍNGUEZ, H.; PARAJÓ, J. C. Advances in the manufacture, purification and applications of xylo-oligosaccharides as food additives and nutraceuticals. Process Biochemistry, Amsterdam, v. 41, n. 9, p. 1913-1923, 2006.

MURATA, T.; USUI, T. Enzymatic synthesis of important oligosaccharide units involved in $\mathrm{N}$-and O-linked glycans. Trends in Glycoscience and Glycotechnology, Weinheim, v. 12, n. 65, p. 161-174, 2000.

NABARLATZ, D.; MONTANÉ, D.; KARDOŠOVÁ, A.; BEKEŠOVÁ, S.; HŘ́íBALOVÁ, V.; EBRINGEROVÁ, A. Almond shell xylo-oligosaccharides exhibiting immunostimulatory activity. Carbohydrate Research, London, v. 342, n. 8, p. 1122-1128, 2007.

NAGARAJAN, D. R.; RAJAGOPALAN, G.; KRISHNAN, C. Purification and characterization of a maltooligosaccharide-forming $\alpha$-amylase from a new Bacillus subtilis KCC103. Applied Microbiology Biotechnology, Oxford, v. 73, n. 3, p. 591-597, 2006.

NAKAJIMA, M.; IMAMURA, H.; SHOUN, H.; HORINOUCHI, S.; WAKAGI, T. Transglycosylation activity of Dictyoglomus thermophilum amylase A. Bioscience Biotechnology and Biochemistry, Tokyo, v. 68, n. 11, p. 2369-2373, 2004.

NAKKHARAT, P.; HALTRICH, D. Purification and characterisation of an intracellular enzyme with $\beta$-glucosidase and $\beta$-galactosidase activity from the thermophilic fungus Talaromyces thermophilus CBS 236.58. Journal of Biotechnology, Netherlands, v. 123, n. 3, p. 304-313, 2006.

NEUTZLING, M. B.; ARAÚJO, C. L. P.; VIEIRA, M. F. A.; HALLAL, P. C.; MENEZES, A. M. B. Freqüência de consumo de dietas ricas em gordura e pobres em fibra entre adolescentes. Revista Saúde Pública, São Paulo, v. 41, n. 3, p. 17-21, 2007.

NONINO, C. B.; BORGES, R. M.; PASQUALI, L. S.; MARCHINI, J. S. Terapia nutricional oral em pacientes com síndrome do intestino curto. Revista de Nutrição, Campinas, v. 14, n. 3, p. 201-205, 2001.
NZEUSSEU, A.; DIENST, D.; HAUFROID, V.; DEPRESSEUX, G.; DEVOGELAER, J.; MANICOURT, D. Inulin and fructo-oligosaccharides differ in their ability to enhance the density of cancellous and cortical bone in the axial and peripheral skeleton of growing rats. Bone, New York, v. 38, n. 3, p. 394-399, 2006.

OHTA, A. Prevention of osteoporosis by foods and dietary supplements. The effect of fructooligosaccharides (FOS) on the calcium absorption and bone. Clinical Calcium, Tokyo, v. 16, n. 10, p. 81-88, 2006.

OKU, T.; NAKAMURA, S. Digestion, absorption, fermentation, and metabolism of functional sugar substitutes and their available energy. Pure and Applied Chemistry, Res Triangle PK, v. 74, n. 7, p. 1253-1261, 2002.

OKU, T.; URA, S. Comparison of digestibility and breath hydrogen gas excretion of fructo-oligosaccharide, galactosyl-sucrose, and isomalto-oligosaccharide in healthy human subjects. European Journal of Clinical Nutrition, London, v. 57, n. 9, p. 1150-1156, 2003.

ONISHI, N.; TANAKA, T. Galacto-oligosaccharide production using a recycling cell culture of Sterigmatomyces elviae CBS8119. Letters in Applied Microbiology, Malden, v. 26, n. 2, p. 136-140, 1998.

PANG, Z.; OTAKA, K.; MAOKA, T.; HIDAKA, K.; ISHIJIMA, S.; ODA, M.; OHNISHI, M. Structure of $\beta$-glucan oligomer from laminarin and its effect on human monocytes to inhibit the proliferation of U937 cells. Bioscience and Biotechnology Biochemistry, Tokyo, v. 69, n. 3, p. 553-558, 2005.

PASANEN, S.; JÄNIS, J.; VAINIOTALO, P. Cello-, malto- and xylooligosaccharide fragmentation by collision-induced dissociation using QIT and FT-ICR mass spectrometry: A systematic study. International Journal of Mass Spectrometry, Netherlands, v. 263, n. 1, p. 22-29, 2007.

PASSOS, L. M. L.; PARK, Y. K. Frutooligossacarídeos: implicações na saúde humana e utilização em alimentos. Ciência Rural, Santa Maria, v. 33, n. 2, p. 385-390, 2003.

PAZUR, J. H. Neutral polysaccharides. In: CHAPLIN, M. F.; KENNEDY, J. F. (Ed.). Carbohydrate analysis: a practical approach. 2th ed. Oxford, U K: Oxford University Press, 1994, p.181.

PERUGINO, G.; TRINCONE, A.; ROSSI, M.; MORACCI, M. Oligosaccharide synthesis by glycosynthases. Trends in Biotechnology, London, v. 22, n. 1, p. 31-37, 2004.

PHILLIPS, G. O.; OGASAWARA, T.; USHIDA, K. The regulatory and scientific approach to defining gum arabic (Acacia senegal and Acacia seyal) as a dietary fibre. 
Food Hydrocolloids, Oxford, v. 22, n. 1, p. 24-35, 2008.

PUCCIO, G.; CAJOZZO, C.; MELI, F.; ROCHAT, F.; GRATHWOHL, D.; STEENHOUT, P. Clinical evaluation of a new starter formula for infants containing live Bifidobacterium longum BL999 and prebiotics. Nutrition, New York, v. 23, n. 1, p. 1, 2007.

RABIU, B. A.; JAY, A. J.; GIBSON, G. R.; RASTALL, R. A. Synthesis and fermentation properties of novel galacto-oligosaccharides by $\beta$-galactosidases from Bifidobacterium species. Applied and Environmental Microbiology, Washington, v. 67, n. 6, p. 2526-2530, 2001.

RAMESH, H. P.; THARANATHAN, R. N. Carbohydrates - the renewable raw materials of high biotechnological value. Critical Reviews in Biotechnology, London, v. 23, n. 2, p. 149-173, 2003.

RAUPP, D. S.; MARQUES, S. H. P.; ROSA, D. A.; CALDI, C. M.; CREMASCO, A. C. V.; BANZATTO, D. A. Arraste via fecal de nutrientes da ingestão produzido por bagaço de mandioca hidrolisado. Scientia Agricola, São Paulo, v. 59, n. 2, p. 235-238, 2002.

REMAUD-SIMON, M.; WILLEMOT, R-M.; SARÇABAL, P.; MONTALK, G. P.; MONSAN, P. Glucansucrases: molecular engineering and oligosaccharide synthesis. Journal of Molecular Catalysis, New York, v. 10, n. 1-3, p. 117-128, 2000.

REZENDE, S. T.; GUIMARÃES, V. M. Enzimas como agentes biotecnológicos. SAID, S.; PIETRO, R. (Ed.). Legis Summa: Ribeirão Preto, 2004, 271 p.

RIVERO-URGELL, M.; SANTAMARIA-ORLEANS, A. Oligosaccharides: application in infant food. Early Human Development, Clare, v. 65, n. 1, p. 43-52, 2001.

ROBERFROID, M. B. Fructo-oligosaccharide mal absorption: benefit for gastrointestinal functions. Current Opinion in Gastroenterology, Philadelphia, v. 16, n. 2, p. 173-177, 2002.

RYCROFT, C. E.; JONES, M. R.; GIBSON, G. R.; RASTALL, R. A. Fermentation properties of gentiooligosaccharides. Letters in Applied Microbiology, Malden, v. 32, n. 3, p. 156-161, 2001.

SAKAMOTO, T.; FUJITA, T.; KAWASAKI, H. Transglycosylation catalyzed by a Penicillium chrysogenum exo-1,5- $\alpha$-L-arabinanase. Biochimica et Biophysica Acta (BBA) - General Subjects, Amsterdam, v. 1674, n. 1, p. 85-90, 2004.

SALYERS, A. A.; PALMER, J. K.; WILKINS, T. D. Laminarinase ( $\beta$-glucanase) activity in bacteroides from the human colon. Applied and Environmental Microbiology, Washington, v. 33, n. 5, p. 1118-1124,
1977.

SANZ, M. L.; CÔTÉ, G. L.; GIBSON, G. R.; RASTALL, R. A. Selective fermentation of gentiobiose-derived oligosaccharides by human gut bacteria and influence of molecular weight. FEMS Microbiology Ecology, Malden, v. 56, n. 3, p. 383-388, 2006.

SCHMID, F.; STONE, B. A.; MCDOUGALL, B. M.; BACIC, A.; MARTIN, K. L.; BROWNLEE, R. T. C.; CHAI, E.; SEVIOUR, R. J. Structure of epiglucan, a highly side-chain/branched $(1,3 ; 1,6)-\beta$-glucan from the micro fungus Epicoccum nigrum Ehrenb. ex Scglecht. Carbohydrate Research, London, v. 331, n. 2, p. $163-$ $171,2001$.

SHOAF, K.; MULVEY, J. L.; ARMSTRONG, G. D.; HUTKINS, R. W. Prebiotic galactooligosaccharides reduce adherence of enteropathogenic Escherichia coli to tissue culture cells. Infection and Immunity, Washington, v. 74, n. 12, p. 6920-6928, 2006.

SHODA, S.; FUJITA, M.; KOBAYASHI, S. Glycanasecatalyzed synthesis of non-natural oligosaccharides. Trends in Glycoscience and Glycotechnology, Weinheim, v. 10, n. 13, p. 279-289, 1998.

SILVA, I. R.; MONTEIRO, N. K.; MARTINEZ, P. F.; IZELI, N. L.; VASCONCELOS, A. F. D.; CARDOSO, M. S.; CORRADI DA SILVA, M. L.; BARBOSA, A. M.; DEKKER, R. F. H.; SILVA, G. V. J.; MORAES, L. A. B. Purificação e caracterização de uma gentioexaose obtida de botriosferana por hidrólise ácida parcial. Química Nova, São Paulo, v. 31, n. 5, p. 1015-1019, 2008.

SMAALI, M. I.; MICHAUD, N.; MARZOUKI, N.; LEGOY, M. D.; MAUGARD, T. Comparison of two $\beta$-glucosidases for the enzymatic synthesis of $\beta-(1 ; 6)$ $\beta$-(1;3)-gluco-oligosaccharides. Biotechnology Letters, Netherlands, v. 26, n. 8, p. 675-679, 2004.

STEGINK, L. D.; ZIKE, W. L.; ANDERSEN, D. W.; KILLION, D. Oligosaccharides as an intravenous energy source in postsirurgical patients: utilization when infused with glucose, amino acids, and lipid emulsion. American Journal of Clinical Nutrition, Bethesda, v. 46, n. 6, p. 461-466, 1987.

SUN, H-J.; YOSHIDA, S.; PARK, N.-H.; KUSAKABE, I. Preparation of $(1 \rightarrow 4)-\beta$-D-xylooligosaccharides from an acid hydrolysate of cotton-seed xylan: suitability of cotton-seed xylan as a starting material for the preparation of $(1 \rightarrow 4)-\beta$-D-xylooligosaccharides. Carbohydrate Research, London, v. 337, n. 7, p. 657-661, 2002.

SUTHERLAND, I. W. Novel and established applications of microbial polysaccharides. Trends in Biotechnology, London, v. 16, n. 1, p. 41-46, 1998. 
TEN BRUGGENCATE, S. J. M.; BOVEEOUDENHOVEN, I. M. J.; LETTINK-WISSINK, M. L. G.; VAN DER MEER, R. Dietary fructo-oligosaccharides dose-dependently increase translocation of salmonella in rats. The Journal of Nutrition, Bethesda, v. 133, n. 7, p. 2313-2318, 2003.

THAMER, K. G.; PENNA, A. L. B. Caracterização de bebidas lácteas funcionais fermentadas por probióticos e acrescidas de prebiótico. Ciência e Tecnologia de Alimentos, Campinas, v. 26, n. 3, p. 589-596, 2006.

TOLSTOGUZOV, V. Functional properties of food proteins and role of protein-polysaccharide interaction. Food Hydrocolloids, Oxford, v. 34, n. 6, p. 571-578, 2004.

TOSH, S. M.; BRUMMER, Y.; WOOD, P. J.; QI, W.; WEISZ, J. Evaluation of structure in the formation of gels by structurally diverse $(1 \rightarrow 3)(1 \rightarrow 4)-\beta$-D-glucans from four cereal and one lichen species. Carbohydrate Polymers, Oxford, v. 57, n. 3, p. 249-259, 2004.

TZORTZIS, G.; JAY, A. J.; BAILLON, M. L. A.; GIBSON, G. R.; RASTALL, R. A. Synthesis of $\alpha$-galactooligosaccharides with $\alpha$-galactosidase from Lactobacillus reuteri of canine origin. Applied Microbiology and Biotechnology, New York, v. 63, n. 3, p. 286-292, 2003.

UKAI, S.; YOKOYAMA, S.; HARA, C.; KIHO, T. Structure of an alkali-soluble polysaccharide from the fruit body of Ganoderma japonicum Lloyd. Carbohydrate Research, London, v. 105, n. 2, p. 237-243, 1982.

UNNO, T.; NAKAKUKI, T.; FUJIMOTO, Y.; OKADA, G.; KAINUMA, S.; GODA, T. Industrial production and higher application of functional $\beta$-glucooligosaccharides having a bitter taste. Journal of Applied Glycoscience, New York, v. 52, n. 1, p. 59-64, 2005.

VANDAMME, E. J.; SOETAERT, W. Biotechnical modification of carbohydrates. FEMS Microbiology Reviews, Malden, v.16, n. 2-3, p.163-186, 1995.

VERGHESE, M.; WALKER, L.; SHACKELFORD, L.; CHAWAN, C. Inhibitory effects of nondigestible carbohydrates of different chain lengths on azoxymethaneinduced aberrant crypt foci in Fisher 344 rats. Nutritional Research, New York, v. 25, n. 9, p. 859-868, 2005.

VESSELS, J. M.; RADDING, J. A. Oligosaccharide mapping of fungal glucan synthase product by highperformance anion-exchange chromatography. Analytical Biochemistry, San Diego, v. 215, n. 1, p. 150-155, 1993.

VITOLO, M. R.; CAMPAGNOLO, P. D. B.; GAMA, C. M. Factors associated with a risk of low dietary fiber intake in adolescents. Jornal de Pediatria, Porto Alegre, v. 83 , n. 1, p. 32-37, 2007.

VODENICAROVÁ, M.; DRÍMALOVÁ, G.; HROMÁDKOVÁ, Z.; MALOVÍKOVÁ, A.; EBRINGEROVÁ, A. Xyloglucan degradation using different radiation sources: A comparative study. Ultrasonic Sonochemistry, New York, v. 13, n. 2, p. 157164, 2006.

WARRAND, J.; JANSSEN, H.-G. Controlled production of oligosaccharides from amylose by acidhydrolysis under microwave treatment: Comparison with conventional heating. Carbohydrate Polymers, Oxford, v. 69, n. 2, p. 353-362, 2007.

WATANABE, H.; NISHIMOTO, T.; KUBOTA, M.; CHAEN, H.; FUKUDA, S. Cloning, sequencing, and expression of the genes encoding an isocyclomaltooligosaccharide glucanotransferase and an alpha-amylase from a Bacillus circulans strain. Bioscience Biotechnology Biochemistry, Tokyo, v. 70, n. 11, p. 1954-1960, 2006.

WONG, C-H. Enzymatic and chemoenzymatic synthesis of carbohydrates. Pure Applied Chemistry, New York, v. 67, n. 10, p. 1609-1616, 1995.

YAMASHITA, A.; HIROYUKI, H.; KOKI, F.; MASAMICHI, O.; SHIGEHARU, M.; SUMIO, K. Reverse reaction of Aspergillus niger AP-9319 $\beta$-Galactosidase in a supersaturated substrate solution: production of $\beta$-linked galacto-oligosaccharide ( $\beta$-GOS). Bioscience Biotechnology Biochemistry, Tokyo, v. 69, n. 7, p. 1381-1388, 2005.

YUASA, H.; HASHIMOTO, H. Recent advances in the development of unnatural oligosaccharides: Conformation and Bioactivity. Trends in Glycoscience and Glycotechnology, Weinheim, v. 13, n. 30, p. 31-55, 2001.

ZAFAR, T. A.; WEAVER, C. M.; ZHAO, Y.; MARTIN, B. R.; WASTNEY, M. E. Nondigestible oligosaccharides increase calcium absorption and suppress bone resorption in ovariectomized rats. The Journal of Nutrition, Bethesda, v. 134, n. 2, p. 399-402, 2004.

ZHANG, L.; LI, X.;XU, X.; ZENG, F. Correlation between antitumor activity, molecular weight, and conformation of lentinan. Carbohydrate Research, London, v. 340, n. 8, p. 1515-1521, 2005.

ZHANG, M.; ZHANG, L.; WANGA, Y.; CHEUNG, P. C. $\mathrm{K}$. Chain conformation of sulfated derivates of $\beta$-glucan from sclerotia of Pleurotus tuber-regium. Carbohydrate Research, London, v. 338, n. 24, p. 2863-2870, 2003. 
Giese, E. C. et al. 